\title{
PID COMBUSTÃO - UM MELHOR CONTROLE PARA QUEIMA DOS GASES EM COQUERIA HEAT RECOVERY*
}

\section{Resumo}

Yan Samuel Ferreira Junqueira ${ }^{1}$ Neussias Inocêncio Henrique ${ }^{2}$ Robson Jacinto Coelho ${ }^{3}$ Luiz Afonso de Andrade ${ }^{4}$ Charles Humberto Effgen Wernesbach ${ }^{5}$ Ulisses de Oliveira Pinto 6

Glauber de Sousa de Araujo ${ }^{7}$

Sandro de Souza Azevedo ${ }^{8}$ Rafael Pedrosa Pereira ${ }^{9}$

O processo de coqueificação em uma Coqueria do tipo Heat Recovery ocorre pela queima da matéria volátil presente no carvão, principal combustível para aquecimento dos fornos. Uma segunda queima não desejada ocorre pela combustão do coque. Essa queima indesejada é denominada Burn Loss. A quantidade de ar succionada para dentro dos fornos era controlada por um sistema automático que abria ou fechava as válvulas utilizando como principal variável o Tempo. Durante o controle por tempo varias influências e distúrbios que ocorriam no processo não eram levadas em consideração e consequentemente não era utilizado todo o potencial do processo para a produção de coque. O controle desenvolvido pela equipe da Coqueria da thyssenkrupp CSA (tkCSA) chamado de PID Combustão é focado em um sistema de autoaprendizagem, capaz de reconhecer as características do processo e admitir somente a quantidade de ar necessária para cada forno. Cálculos matemáticos, estatísticos e o histórico da temperatura do forno são levados em consideração pelo PID Combustão que otimiza a mistura de gás com ar no forno. Os principais benefícios após a instalação do PID Combustão foram: redução nas temperaturas dos coletores (preservação do ativo), aumento da capacidade de produção do forno (aumento da velocidade de coqueificação) e otimização da sucção ao longo dos fornos no mesmo coletor.

Palavras-chave: Coqueria heat recovery; Combustão; Gases de coqueria; Controle PID.

\section{PID COMBUSTION - A BETTER CONTROL FOR BURNING GAS IN A HEAT RECOVERY COKE} PLANT

\section{Abstract}

The coking process in a Heat Recovery Coke Plant is founded on the burn of volatile matter, present on coal as primary fuel. A second unwanted reaction occurs by the combustion of coke. This undesired burning process is called Burn Loss. The amount of air sucked to the oven was controlled by an automatic system which open or close the valves using as main variable Time. During the control by Time various influences which occur in process are not considered, and consequently not all process potential to produce coke are used. The control developed by the maintenance, operation and technical unit team in thyssenkrupp CSA (tkCSA), named PID Combustion, was focused on a self-taught system, able to recognize the disturbs of the process and admit only the amount of air required for each oven. Mathematical, statistical calculations and the heat historical of the oven are evaluated by the PID Combustion which will optimize the mix of gas and air on the oven. The main benefits after deployment were: decrease in temperature collectors (preservation of assets), oven production capacity increased (increase cooking speed) and suction optimization along the oven in the same collector.

Keywords: Heat recovery coke plant; Combustion; Coke plant gases; PID controller.

Eng. de Controle e Automação, Eng. de Processos Sênior, Thyssenkrupp CSA, RJ, RJ, Brasil.

Engenharia Química, Engenheiro de Processo Junior, Thyssenkrupp CSA, Rio de Janeiro, RJ, Brasil.

Engenharia Metalúrgica, Mestrado em Engenharia de Materiais, Engenheiro Especialista em Redução, Thyssenkrupp CSA, Rio de Janeiro, RJ, Brasil.

4 Master Comercio Exterior e Finanças Internacionais, Coordenador Unidade Técnica Coqueria, Thyssenkrupp CSA, Rio de Janeiro, RJ, Brasil.

5 Tecnólogo em Mecânica, Coord. Preservação Bateria Coqueria, Thyssenkrupp CSA, RJ, RJ, Brasil.

6 Técnico em Química Industrial, Supervisor Operação Coqueria, Thyssenkrupp CSA, RJ, RJ, Brasil.

7 Administração de Empresas, Técnico de Qualidade, Thyssenkrupp CSA, Rio de Janeiro, RJ, Brasil.

8 Téc. em Eletromecânico, Téc. Especialista Refratário, Thyssenkrupp CSA, Rio de Janeiro, RJ, Brasil.

9 Eng. de Controle e Automação, Eng. de Automação Pleno, Thyssenkrupp CSA, RJ, RJ, Brasil. 


\section{INTRODUÇÃO}

A Coqueria da thyssenkrupp CSA (tkCSA) utiliza a tecnologia Heat Recovery para produção de coque e de vapor como subproduto do processo. A matéria volátil presente no carvão é utilizada como combustível para aquecimentos dos fornos. $\mathrm{O}$ ar necessário para ocorrer à combustão é succionado da atmosfera através de exaustores fazendo o processo trabalhar com pressão negativa.

Os fornos como mostra a Figura 1, possuem as seguintes dimensões, 13,3 metros de comprimento, 3,6 metros de largura e 2,4 metros de altura. $O$ forno é dividido em duas câmaras de combustão, primária e secundária (topo e Sole Flue respectivamente). O topo é composto por seis entradas de ar e a soleira composta por dezesseis entradas de ar.

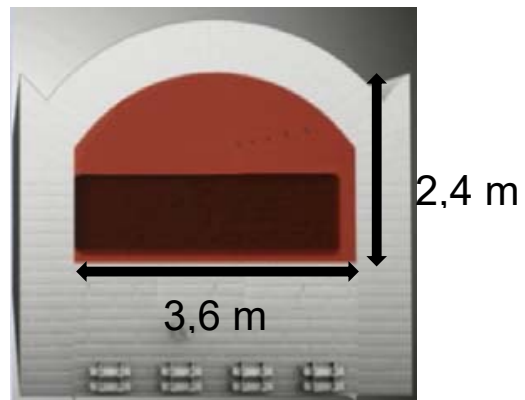

Figura 1. Dimensões do forno.

O processo de queima da matéria volátil ocorre em duas etapas. Primeiramente o ar succionado no topo dos fornos reage com os gases provenientes da massa de carvão enfornada, nessa etapa ocorre à queima de aproximadamente $60 \%$ dos gases. Os gases remanescentes são succionados para a soleira pelos Donw Comers. No Sole Flue o ar é distribuído nos dezesseis pontos onde ocorre a combustão secundária (remanescente). Após os gases percorrerem toda a extensão da soleira e serem queimados, os fumos são enviados aos coletores via Up Takes. A Figura 2 exemplifica o processo de queima nos fornos.

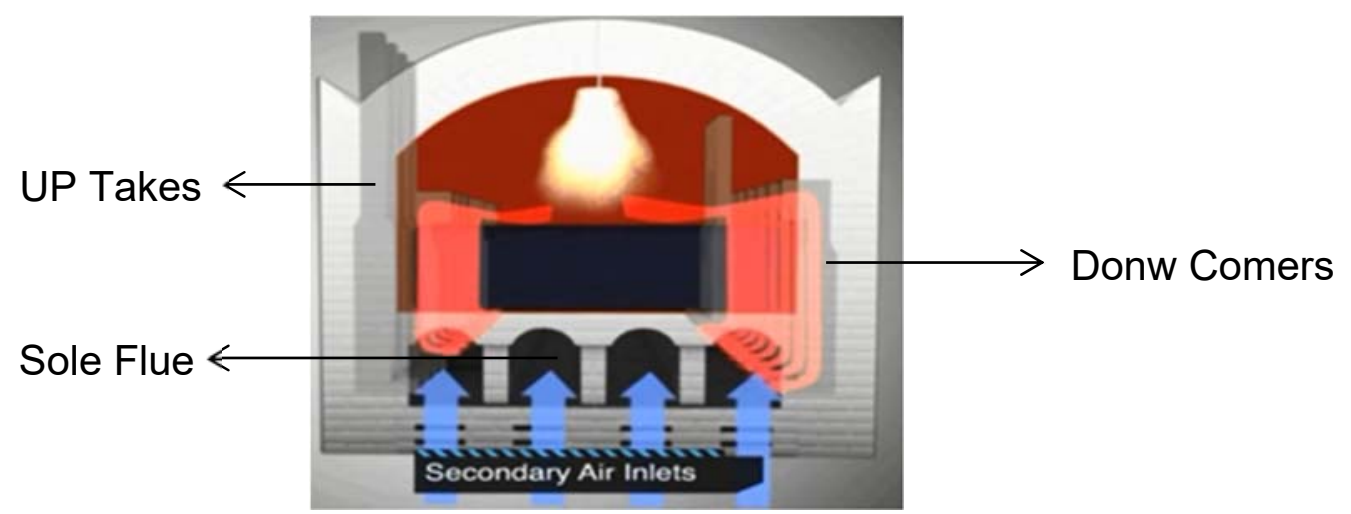

Figura 2. Exemplificação da combustão no topo e soleira.

O coletor tem como objetivo transportar os gases queimados durante a combustão até as caldeiras onde a energia térmica será utilizada para a produção de vapor. Após essa etapa existe o processo de dessulfuração FGD (Full Gas Desulfurization) para limpeza dos gases antes de ser enviada a chaminé. 


\section{INFLUÊNCIAS NO PROCESSO HEAT RECOVERY}

\# \#

A temperatura dos fornos deve ser mantida dentro da faixa ótima de operação para maximizar o processo de coqueificação.

Durante o processo de coqueificação a queima da matéria volátil, principal combustível do forno, sofre influência de vários parâmetros externos que afetam diretamente a temperatura dos fornos, sendo os principais mostrados na Tabela 1.

Tabela 1. Parâmetros externos que influenciam o processo de coqueificação.

\begin{tabular}{|c|c|c|}
\hline \multicolumn{3}{|c|}{ INFLUÊNCIAS NO PROCESSO HEAT RECOVERY } \\
\hline Matéria Prima & Estrutura dos Fornos & Controle de Processo \\
\hline $\begin{array}{l}\text { - Matária Volátil } \\
\text { - Umidade da mistura de carvão } \\
\text { - Cinza }\end{array}$ & $\begin{array}{l}\text { - Projeto da soleira dos fornos } \\
\text { - Sistema de isolamento dos fornos } \\
\text { - Vedação das portas } \\
\text { - Quantidade e projeto das entradas de ar } \\
\text { - Qualidade do refratário }\end{array}$ & $\begin{array}{l}\text { - Temperatura no incío do enfornamento } \\
\text { - Altura da carga enfornada } \\
\text { - Densidade da massa enfornada } \\
\text { - Perda de calor } \\
\text { - Volume da câmara de combustão } \\
\text { - Cinza } \\
\text { - Pressão de succção dos gases } \\
\text { - Volume de ar para combustão } \\
\text { - Tempo de residência } \\
\text { - Entrada de ar falso } \\
\text { - Habilidade dos operadorees } \\
\text { - Disponiblidade de máquina }\end{array}$ \\
\hline
\end{tabular}

Esses parâmetros afetam a geração de gases dentro do forno e consequentemente a combustão que mantem o forno aquecido pode perder eficiência.

\subsection{GERAÇÃO DE GASES E QUEIMA NO FORNO}

\#

Logo após o enfornamento da massa de carvão, inicia-se o processo de coqueificação, com a liberação de gases proveniente da matéria volátil. A geração de gases tende a seguir a curva teórica, apresentada na Figura 3.

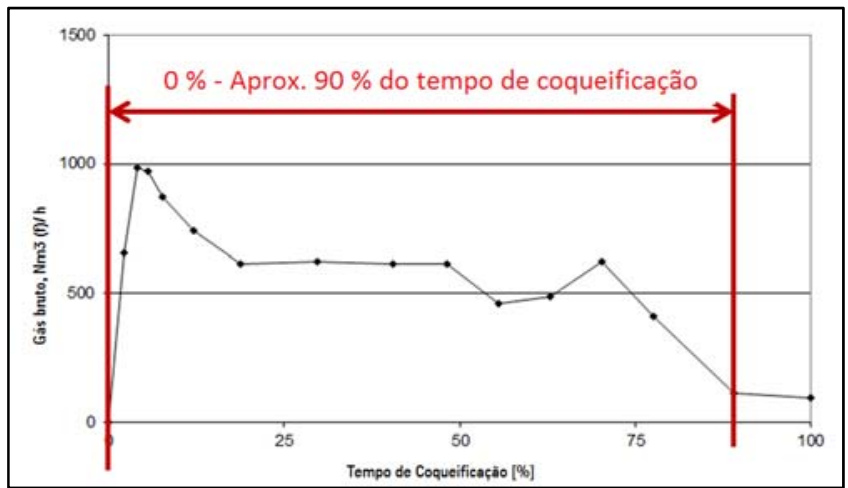

Figura 3. Geração de gases durante processo de coqueificação.

Com o objetivo de maximizar a queima e manter os fornos com a máxima temperatura possível durante o processo, o volume de ar succionado no forno deve acompanhar na mesma proporção às oscilações da geração.

Devido às influências que ocorrem no processo, a geração de gases tende a divergir da curva teórica, neste caso, o volume de ar succionado deve variar de acordo com a geração de gases real no forno. 
No inicio do processo necessitamos de uma grande quantidade de ar para ocorrer à completa combustão, após aproximadamente 10 horas o volume de gás gerado começa a diminuir fazendo com que o gás enviado a soleira seja menor, consequentemente a quantidade de ar na soleira não necessita ser máxima.

No final do processo de coqueificação, os gases gerados são queimados somente na câmara primária, sendo assim, a quantidade de ar succionado deve ser reduzida, pois caso ocorra excesso de ar o mesmo irá reagir com o próprio coque, reduzindo o volume de produção (Burn Loss).

\subsection{ENTRADAS DE AR NOS FORNOS}

A Coqueria no inicio das operações não possuía um sistema automático de controle para admissão de ar. A Figura 4 apresenta a concepção original das entradas de ar no topo e na soleira dos fornos.
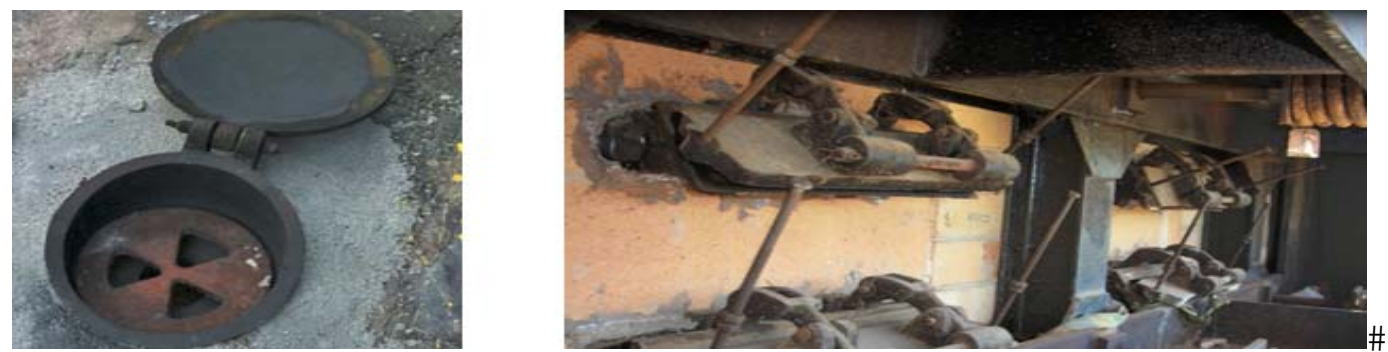

Figura 4. Primeira entrada de ar no topo e soleira.\#

Neste período, a operação dessas válvulas era realizada manualmente, onde o operador fechava a entrada de ar quando o forno não apresentava mais gases para serem queimados.

A fim de melhorar a qualidade do processo e otimizar a queima dos gases foi implantado um sistema automático com válvulas motorizadas e controle via PLC para que a abertura das válvulas fosse realizada automaticamente.

\subsection{CONTROLE VIA TEMPO}

A instalação das válvulas automáticas proporcionou realizar todas as movimentações para o ajuste da quantidade de ar necessária dentro do forno baseado na curva teórica de geração de gases.

O controle automatizado garantiu que todos os fornos tivessem suas válvulas abrindo e fechando em tempos definidos. A Figura 5 mostra como era realizada a abertura das válvulas em modo automático baseado no Tempo de Coqueificação.

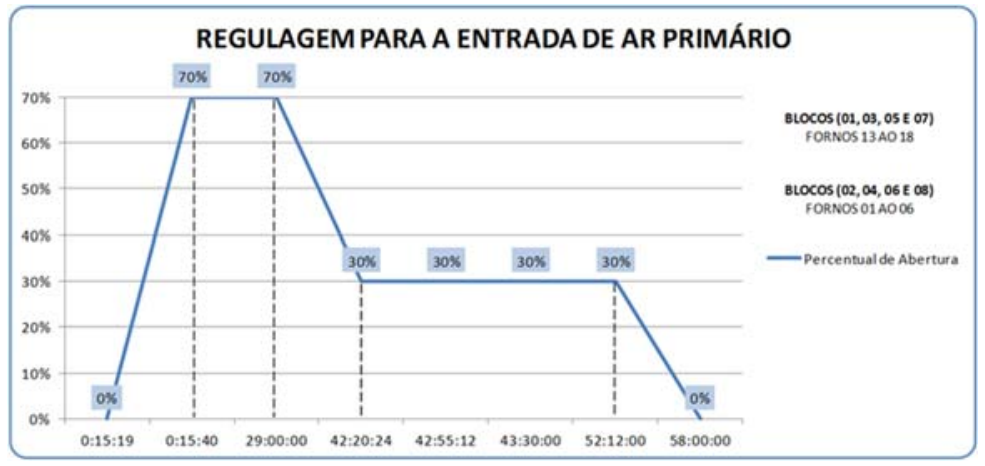

Figura 5. Regulagem da válvula topo no controle via Tempo.\# 
Após o período de inicio de operação, estabilização das maquinas móveis e aumento da produção alguns problemas começaram a ocorrer.

O controle das válvulas dos fornos baseado no tempo de coqueificação e na curva teórica de geração de gases trouxe alguns problemas, pois não consideravam as variáveis do processo que influenciam a geração de gases, como mencionado no capítulo dois (Influências no processo Heat Recovery).

Exemplificando um problema no controle automático via TEMPO, caso as válvulas iniciassem o fechamento na soleira e ainda existissem gases, esses deixariam de serem queimados dentro do forno e seriam enviados ao coletor, ocasionando a indesejada combustão no coletor.

A queima dos gases nos coletores gera danos à estrutura refratária e metálica das baterias.

Caso um coletor venha a sofrer danos algumas ações são necessárias:

- Reparo do coletor.

- Redução da massa de carvão enfornada em todos os fornos do bloco ocasionado a redução da produção de coque e consequentemente de vapor.

Para reduzir o efeito da queima de gases ricos nos coletores, era modificada a parametrização da abertura das válvulas na soleira a fim de deixa-las mais tempo abertas. Essa atuação, de imediato, parecia ser a solução do problema, mas em longo prazo ocorria a redução da temperatura ou resfriamento da soleira. Caso esse fenômeno continue ocorrendo, o processo começa a perder rendimento, uma vez que está sendo utilizada a sucção para admitir ar na soleira mesmo não existindo gás.

É importante ressaltar que o controle automatizado via TEMPO obteve sucesso se comparado ao controle manual no campo. Porém para o aumento de produção de coque era necessário desenvolver outra forma de controle para admissão de ar, a fim de minimizar os danos nos coletores e garantir a maximização da combustão e da reserva térmica dos fornos.

\subsection{CONTROLE VIA PID COMBUSTÃO}

O principal objetivo do controle PID Combustão é garantir que a combustão na soleira e topo seria maximizada, uma vez que a admissão de ar se dará na mesma proporção da quantidade de gases gerados dentro do forno.

O PID Combustão trabalha com a geração de gases durante o processo de coqueificação e com a temperatura dos fornos. As válvulas de admissão de ar abrem e fecham para garantir que a reação de combustão entre os gases provenientes da câmara primária com o ar da atmosfera seja completa.

O controle via PID Combustão, verifica durante todo o processo as variações de temperaturas e caso algum distúrbio ocorra as válvulas da soleira irão modular para otimizar a queima.

O controle da válvula do topo irá modular a válvula para que após certa temperatura e tempo de coqueificação, seja iniciado o fechamento gradual, a fim de otimizar a relação ar/ gás.

\subsection{DIFERENÇAS ENTRE CONTROLE VIA TEMPO E PID COMBUSTÃO}

A Figura 8 apresenta um comparativo entre o controle Tempo e PID Combustão. 0 forno foi controlado via PID Combustão. Observa-se que a válvula da soleira ficou aberta em $100 \%$ por um período maior do que controle via Tempo. Caso o controle 
via Tempo estivesse em operação, grande parte dos gases que não foram queimados dentro da soleira, seriam enviados para o coletor.

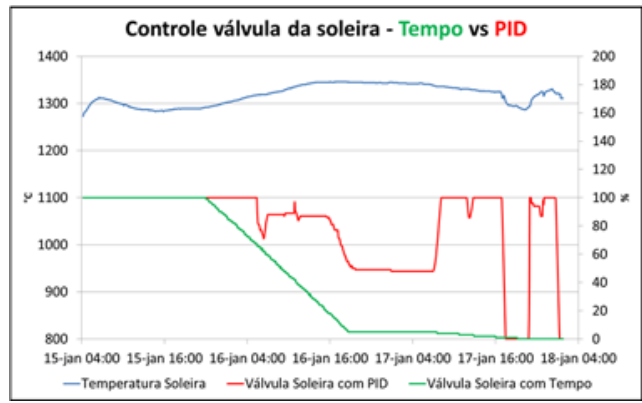

Figura 8. Diferença entre controle TEMPO e PID Combustão para válvula da soleira.

Observa-se ainda que após o completo fechamento da soleira, ocorre no fim do ciclo de coqueificação um distúrbio no processo e uma grande quantidade de gases é enviada a soleira. Nesse caso, com o controle PID Combustão a válvula retorna a abrir e os gases são queimados dentro do forno. No controle via Tempo não haveria mudança na abertura da válvula, pois a curva teórica não considera distúrbios no processo.

O PID Combustão também atua na válvula do topo a fim de minimizar a queima de coque, a Figura 9 apresenta a diferença nos controles. Observa-se que a válvula do topo no controle PID Combustão inicia um fechamento gradativo a partir de certo ponto da temperatura da câmara primária. Caso o controle via Tempo estivesse em operação ocorreria grande queima de coque.

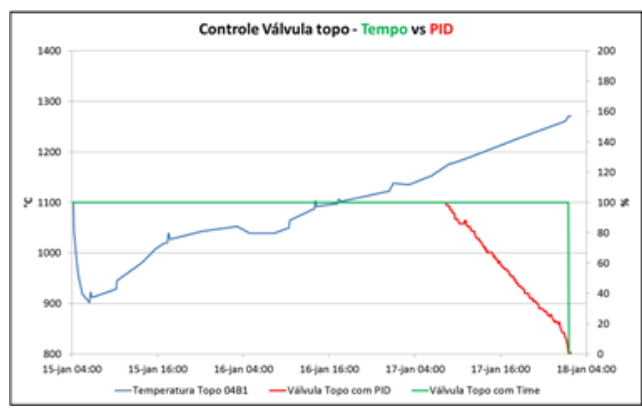

Figura 9. Diferença entre controle TEMPO e PID Combustão para válvula do topo.

É importante ressaltar que mesmo se o controle via tempo fosse modificado para um fechamento gradativo, este ainda estaria ligado diretamente ao tempo de coqueificação e não à temperatura do topo.

No controle PID Combustão, caso a quantidade de ar succionado no topo, no fim do processo de coqueificação, não seja suficiente para queimar os gases na câmara primária, a queima ocorrerá na soleira, uma vez que, o controle via PID Combustão abrirá novamente as válvulas da câmara secundária.

\section{RESULTADOS E DISCUSSÃO}

O primeiro teste do PID Combustão ocorreu no final do primeiro semestre de 2015 no bloco C8, onde 18 fornos foram controlados via PID Combustão. Após um mês sem modificações no controle, os resultados foram analisados e foi verificado: 
- Aumento na velocidade de coqueificação (capacidade de transformar carvão em coque).

- Redução na combustão dentro do coletor C8 (melhor combustão dentro dos fornos) e consequentemente preservação do ativo.

- Redução da diferença de sucção entre os fornos.

A implementação do PID Combustão no bloco C8 teve um impacto positivo no processo do bloco $\mathrm{C} 4$, devido os blocos serem conectados a mesma caldeira e exaustor. $\mathrm{O}$ melhor controle da entrada de ar nos fornos do bloco C8 permitiu uma melhor equalização de sucção, que consequentemente beneficiou o bloco C4. Durante o período do teste o bloco $\mathrm{C} 4$ foi mantido com o controle Tempo.

No início do segundo semestre de 2015 toda a Coqueria estava operando com o PID Combustão, os resultados foram:

- Aumento das temperaturas médias do topo e soleira.

- Redução das temperaturas dos coletores.

- Aumento da velocidade de coqueificação e redução no tempo líquido.

\subsection{REDUÇÃO DOS NTE'S}

Com o objetivo de melhorar o controle de temperatura elevadas nos coletores de gases, visto que o uso de média pode mascarar os resultados, foi criado um indicador para cálculos diários. O NTE (Número de Temperaturas Excedidas) é computado sempre quando a temperatura de um coletor ultrapassa o limite estabelecido por mais de 1 hora. Caso a temperatura do coletor fique durante 8 horas do dia acima do limite, o NTE desse coletor será oito. A Figura 10 apresenta a comparação na quantidade de NTE's nos blocos C8 e C4 antes e durante o teste do PID Combustão.

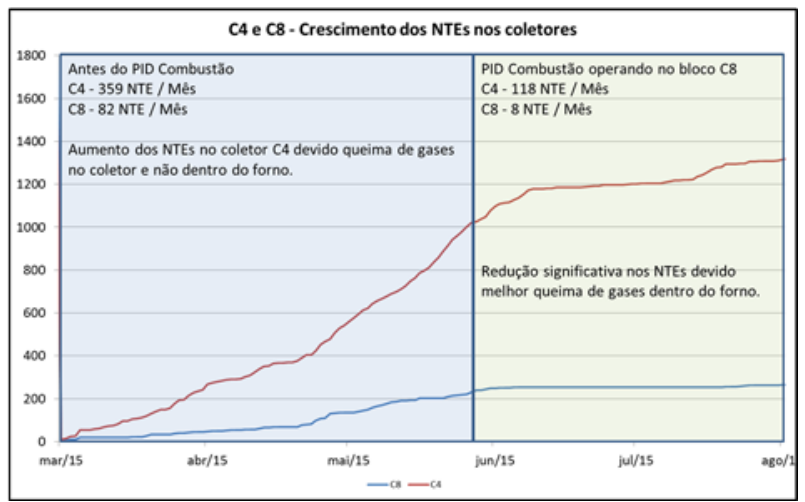

Figura 10. Redução na quantidade de NTEs nos blocos C4 e C8.

Verifica-se que após a implantação do PID Combustão ocorreu uma redução de $68 \%$ e $90 \%$ na quantidade de NTE's nos blocos C4 e C8 respectivamente.

A Figura 11 apresenta o total de NTE's por coletor para cada mil toneladas produzidas. A partir de junho de 2015, com a implantação do PID Combustão, houve uma estabilização em 15 NTE's para cada mil toneladas. Em outubro de 2015, com a entrada do novo modelo operacional da coqueria, houve a redução para uma média de 12 NTE's/kt (até dezembro). A partir de janeiro de 2016, com novas melhorias no controle PID Combustão, o NTE nos coletores reduziu para uma média de 8 NTE's/kt. 


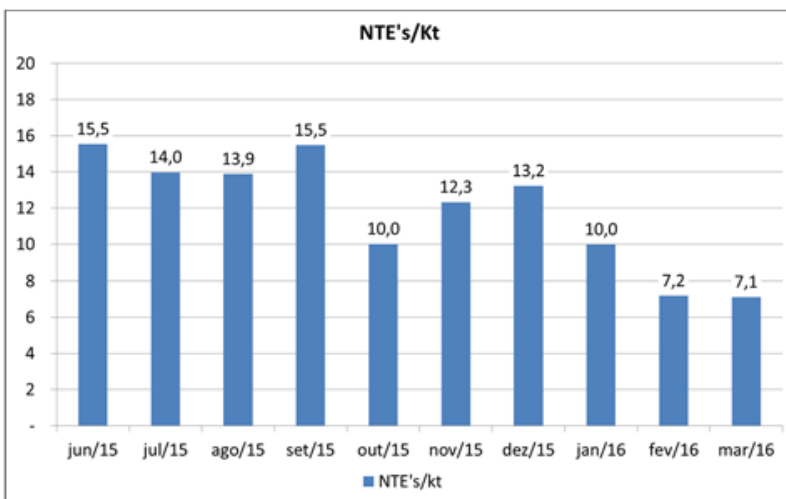

Figura 11. Total de NTE's nos coletores para cada tonelada de coque produzida.

\subsection{AUMENTO DA RESERVA TÉRMICA DOS FORNOS}

O controle via PID Combustão permitiu o aumento do rendimento da queima dos gases dentro dos fornos e proporcionou um aumento da temperatura no topo e na soleira, a Figura 12 apresenta os resultados por bateria.
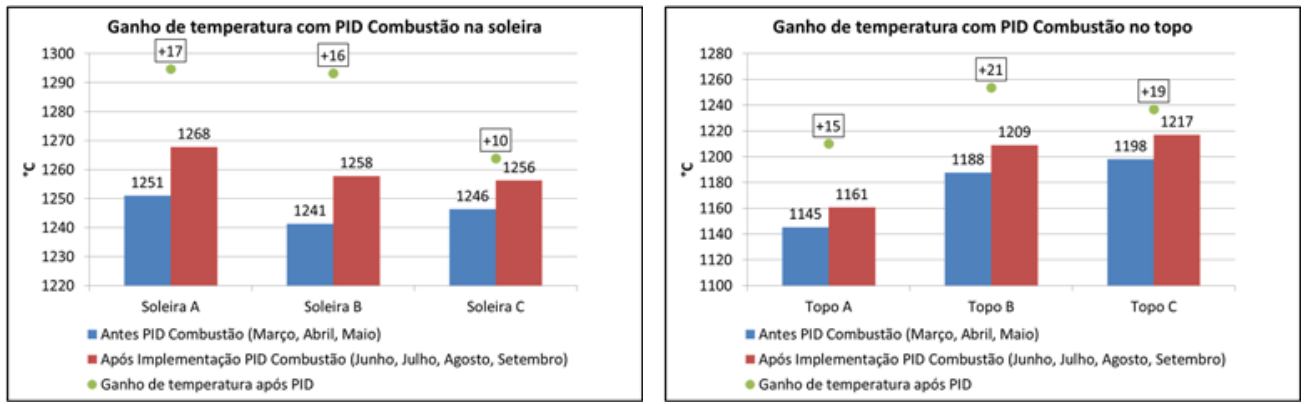

Figura 12. Aumento da temperatura da soleira e topo após implantação do PID.

\subsection{REDUÇÃO DO TEMPO LÍQUIDO DE COQUEIFICAÇÃO}

Devido ao aumento das temperaturas do topo e soleira, a velocidade de coqueificação foi elevada e consequentemente o tempo líquido de coqueificação foi reduzido de 70 horas para 66 horas, conforme apresentado na Figura 13.

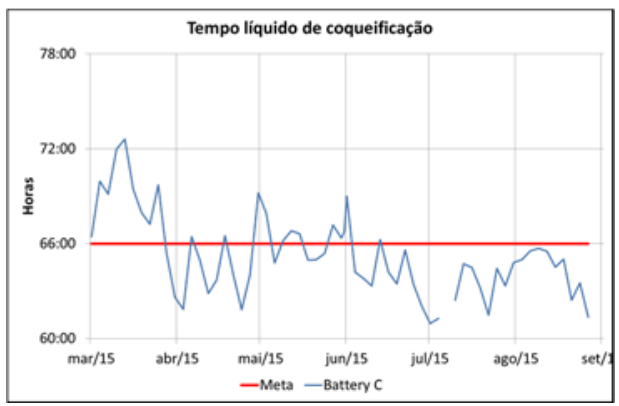

Figura 13. Redução no tempo líquido de coqueificação.

A redução do tempo de coqueificação associado a uma melhor disponibilidade de equipamentos e ainda a redução do tempo de paradas programadas para manutenção de média de 104 horas por mês, para 24 horas por mês, a partir de março de 2016, proporcionou a implantação de um novo modelo operacional com o objetivo de aumentar a produção de 1,5 Mt/a para 1,65 Mt/a. 


\section{CONCLUSÃO}

A lógica do PID Combustão otimizou a admissão de ar dentro dos fornos de coque, e permitiu a admissão de ar na quantidade necessária para garantir que a relação estequiométrica de ar/ gás seja alcançada.

O controle da entrada de ar utilizando PID Combustão proporcionou uma mudança na forma de admissão ar nos fornos e obteve resultados expressivos em vários pontos do processo.

Os principais resultados foram:

- Redução da queima dos gases nos coletores. Preservação do ativo.

- Maior queima dos gases dentro dos fornos.

- Aumento da temperatura dos fornos (dentro dos limites especificados).

- Redução no tempo líquido dos fornos de 70 para 66 horas.

- Aumento da velocidade de coqueificação dos fornos mais afastados da caldeira

Um dos vetores que contribuiu para o aumento de produção de coque de 1,5 Mt/a para 1,65 Mt/a foi a implantação do controle via PID Combustão em toda a Coqueria, devido o aumento da velocidade de coqueificação, com consequente redução do tempo líquido de coqueificação de 70 para 66 horas.

O trabalho em equipe da Manutenção, Operação e Unidade Técnica mostrou-se mais uma vez de suma importância e os resultados mostram que é possível cada vez mais a Coqueria da thyssenkrupp CSA (tkCSA) atingir novos patamares de produção e qualidade de processo.

\section{REFERÊNCIAS}

1 Ronald Kim, Franz-Josef Schuecker. Coke Oven with optimized control and method of control. Patent Publication Number: 20090032382. Date of Patent: Jun 18, 2013.

2 Westbrook, Richard W. Coke oven flue gas sharing. Patent Publication Number: US6596128 B2. Date of Patent: Jul 22, 2003.

3 Coelho, Robson Jacinto. Modelos de previsão de qualidade metalúrgica do coque a partir da qualidade dos carvões individuais e do coque obtido no forno piloto de coqueificação da CST. Dissertação (Mestrado) - Universidade Federal de Ouro Preto. Rede Temática em Engenharia de Materiais, 2003.

4 Junqueira, Yan Samuel Ferreira. "Stamping Charger com automatismo" - Compactação da MASSA DE CARVÕES - Estudo teórico e análise pratica na TKCSA. Contribuição técnica ao $44^{\circ}$ Seminário de Redução de Minério de Ferro e Matérias-primas, $15^{\circ}$ Simpósio Brasileiro de Minério de Ferro e $2^{\circ}$ Simpósio Brasileiro de Aglomeração de Minério de Ferro, 15 a 18 de setembro de 2014, Belo Horizonte, MG, Brasil. 